\title{
AUTORA:
}

Paula Maria Silveira Soares Moura

ORIENTADORA:

\section{Programa de hierarquização do atendimento ao parto e nascimento - Mortalidade perinatal, 2001-2006}

Marilza Vieira Cunha Rudge

CO-ORIENTADORA:

Hierarchization of delivery and birthcare - Perinatal mortality, 2001-2006

IZILDINHA MAESTÁ

\section{Resumo de tese}

Palavras-chave:

Mortalidade perinatal

Fatores de risco

Classificação

Nivel de atenção

Keywords:

Perinatal mortality

Risk factors

Classification

Care level
Dissertação apresentada ao Programa de Pós-graduação em Ginecologia, Obstetrícia e Mastologia da Faculdade de Medicina de Botucatu-UNESP, Área de Concentração: Obstetrícia, para obtenção do título de Mestre, em 26 de fevereiro de 2009.

OBJETIVO: Avaliar as causas e fatores de risco mais freqüentes associados com óbito perinatal em dois centros de diferentes níveis de atenção à saúde. MÉTODOS: Estudo caso-controle de 299 óbitos perinatais (casos) e 1161 recémnascidos sobreviventes ao período neonatal precoce (controles) entre 2001 e 2006 em dois hospitais de diferentes níveis de atenção (secundária e terciária) do município de Botucatu/SP. Foram investigados fatores maternos, gestacionais e neonatais associados com óbitos perinatais. As causas básicas dos óbitos perinatais foram estratificadas em cinco grupos de acordo com a classificação de Wigglesworth modificada por Keeling et al. Foi realizada correlação entre variáveis do estudo e óbito perinatal por análise univariada, seguida de regressão logística múltipla para obtenção de estimativas independentes para o risco de óbito perinatal. Odds ratio foi calculado com intervalo de confiança a 95\%. RESULTADOS: No centro de atenção terciária, fatores de risco para óbito perinatal incluíram idade gestacional, primiparidade, gênero masculino e doença materna (hipertensão arterial, infecção intra-uterina). No centro de atenção secundária, nenhum fator de risco foi identificado, porém Apgar de quinto minuto $<7$, baixo peso ao nascer e hemorragia materna foram associados com óbito perinatal. As causas mais freqüentes de óbito perinatal no centro secundário foram asfixia e morte anteparto, enquanto no terciário prevaleceu malformação seguida por imaturidade e morte anteparto. CONCLUSÃO: Os resultados mostram que atenção obstétrica e neonatal estão integradas num sistema hierarquizado. As causas e fatores associados ao óbito perinatal diferenciaram os dois níveis de atenção à saúde, secundária e terciária. 